\title{
Mixed tumors of the vagina: an immunohistochemical study of 13 cases with emphasis on the cell of origin and potential aid in differential diagnosis
}

\author{
Esther Oliva, Lucia Gonzalez, Adriana Dionigi and Robert H Young \\ James Homer Wright Pathology Laboratories, Massachusetts General Hospital, Harvard Medical School, \\ Boston, MA, USA
}

\begin{abstract}
Mixed tumors of the vagina (MTsV) are rare benign neoplasms characterized by an admixture of welldifferentiated epithelial cells and stromal-type cells in various proportions. In contrast to mixed tumors in other anatomic sites, the histogenesis of the vaginal tumors is unclear. We studied the immunohistochemical profile of 13 examples to explore their histogenesis and determine whether their immunohistochemical profile might be useful in the differential diagnosis. The panel of antibodies used and the number of cases studied were: AE1/ 3 (12), cytokeratin 7 (CK7) (13), cytokeratin 20 (CK20) (13), epithelial membrane antigen (EMA) (13), muscle actin (MA) (12), desmin (11), h-Caldesmon (13), CD10 (13), CD34 (11), CD99 (8), and S-100 (7). Eight out of 12 tumors were positive for AE1/3, 7/13 for CK7, 2/13 for CK20, and 6/13 for EMA. MA was positive in 11/12 mixed tumors, desmin in 10/11 tumors and $h$-Caldesmon in 5/13. All tumors were extensively positive for CD10; CD34 was positive in $7 / 11$; and none out of eight tumors showed membranous CD99 staining. Focal S-100 immunoreactivity was seen in 1/7 tumors. These results show that MTsV coexpress epithelial and mesenchymal markers. The expression of muscle actin (usually extensive), and focal desmin and h-Caldesmon positivity suggests the presence of a smooth muscle or myoepithelial component; however, the S-100 negativity and diffuse CD10 expression argue against it. Positivity for muscle markers does not help distinguish MTsV from smooth muscle or skeletal muscle tumors. The frequent expression of CD10 negates its use in the differential diagnosis with endometrial stromal tumors, and the CD10 and CD34 expression suggests that mixed tumors may arise from a primitive pluripotential cell. MTsV are positive for $h$-Caldesmon and CD10, two markers that have been used in gynecologic pathology primarily to aid in establishing the smooth muscle or endometrial stromal phenotype of a neoplasm.
\end{abstract}

Modern Pathology (2004) 17, 1243-1250, advance online publication, 21 May 2004; doi:10.1038/modpathol.3800173

Keywords: vagina; mixed tumors; immunohistochemistry; histogenesis

Mixed tumors of the vagina (MTsV), also recently designated as spindle cell epitheliomas, ${ }^{1}$ are rare tumors. Since the first description of this tumor in $1953,{ }^{2}$ no more than 50 cases have been reported in the English language literature to the best of our knowledge. ${ }^{1-17}$ In other anatomic locations, the term mixed tumor is typically used to designate a neoplasm composed of epithelial and myoepithelial cells. Those occur most frequently in the salivary gland $;^{18-20}$ however similar tumors have been re-

Correspondence: Dr E Oliva, MD, Department of Pathology, Massachusetts General Hospital, 55 Fruit Street, Boston, MA 02114, USA.

E-mail: eoliva@partners.org

Received 13 November 2003; revised 18 February 2004; accepted 19 February 2004; published online 21 May 2004 ported in the breast, ${ }^{21,22}$ skin, ${ }^{23}$ vulva, ${ }^{24}$ external auditory canal, ${ }^{25}$ trachea, ${ }^{26}$ lacrimal gland, ${ }^{27}$ and soft tissue. ${ }^{28}$ In contrast, MTsV show a different histo logic appearance and myoepithelial cells are not known to exist either in the vagina or in vaginal glandular inclusions. There is no clear origin of these tumors, although several relatively recent studies have proposed an origin from urogenital sinus-derived epithelium based upon the high frequency of these neoplasms near the hymenal ring and strong immunohistochemical and ultrastructural evidence for an epithelial origin., ${ }^{1,3,7}$ The purpose of this study was to investigate the immunohistochemical profile of these tumors, in order to contribute to knowledge of their histogenesis and also to see if their immunohistochemical profile may be useful in their differential diagnosis. 


\section{Materials and methods}

Tissue blocks of $13 \mathrm{MTsV}$ were retrieved from the consultation files of one of us (RHY) and Dr Robert E Scully, and from the archives of the Massachusetts General Hospital. After confirmation of the diagnosis by examination of $4-\mu \mathrm{m}$ hematoxylin and eosin-stained slides (Figure 1a), paraffin-embedded tissue for each case was deparaffinized and subjected to heat-induced epitope antigen retrieval using an electric pressure cooker set at $120^{\circ} \mathrm{C}$ for $5 \mathrm{~min}$. Sections were incubated for $5 \mathrm{~min}$ in $3 \%$ hydrogen peroxide to quench endogenous tissue peroxidase. As the tissue source was primarily from consultation material from different hospitals, tissue fixation may have varied. Immunohistochemistry
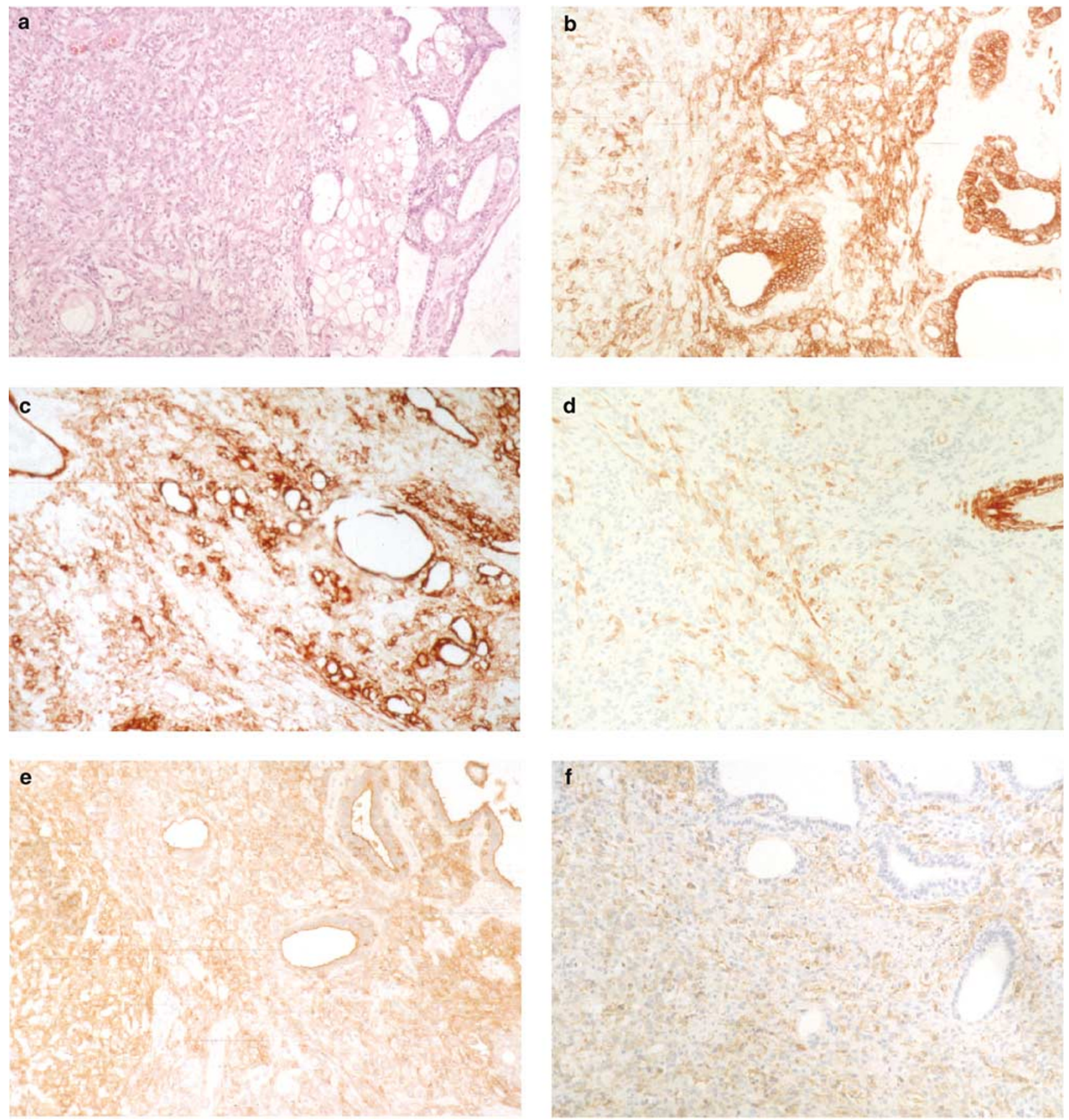

Figure 1 (a) MTV. The tumor is composed of glands, squamous epithelium, and stromal- like cells. (b) AE1/3 shows diffuse and strong positivity in both obvious epithelial and stromal-like cell components. (c) Glandular lining and stromal-like cells are strongly positive for CK7. (d) h-Caldesmon shows strong positivity in the stromal-like cells. (e) Both epithelial and stromal-like elements are diffusely and strongly positive for CD10. (f) CD34 is extensively positive in the stromal-like cells. 
was performed using the avidin-biotin-complex kit (Dako Corp., Carpinteria, CA, USA). The source and dilution of antibodies are shown in Table 1. Immunohistochemical stains were performed for cytokeratin 7 (CK7), cytokeratin 20 (CK20), epithelial membrane antigen (EMA), h-Caldesmon, and CD10 in 13 specimens, AE1/3 and smooth muscle actin in 12 cases, desmin and CD34 in 11 cases, CD99 in eight, and S100 in seven specimens. Scoring was based upon the percentage of positive tumor cells in the epithelial and stromal-like components. However, five tumors did not have a clearcut epithelial component in the block available for immunohistochemistry. The intensity of the immunostaining was graded as $1+$ to $3+$. Tumors in which rare scattered cells $(<5 \%)$ were immunoreactive for specific markers were recorded as such but were considered negative. Although the stromallike cells of these tumors may be epithelial in derivation in this presentation for clarity sake, the overt epithelial areas are referred to as 'epithelial' and the spindle cell areas as 'stromal-like'.

\section{Results}

The immunohistochemical results are summarized in Table 2. AE1/3 was positive in eight out of 12 tumors (Figure 1b). The epithelial component was $3+$ positive in $5 / 6$ cases and one tumor was $1+$. The percentage of positive cells varied from 30 to $90 \%$. One tumor showed $<1 \%$ of positive cells and

Table 1 Source and dilution of antibodies

\begin{tabular}{lll}
\hline AE1/3 & $1: 40 \mathrm{M}$ & Dako Corp., Santa Barbara, CA, USA \\
CK7 & $1: 30 \mathrm{M}$ & Dako Corp., Santa Barbara, CA, USA \\
CK20 & $1: 40$ & Dako Corp., Santa Barbara, CA, USA \\
MA & Net M & Biogenex, San Ramon, CA, USA \\
Desmin & $1: 320 \mathrm{M}$ & Dako Corp., Santa Barbara, CA, USA \\
h-Caldesmon & $1: 160 \mathrm{M}$ & Dako Corp., Santa Barbara, CA, USA \\
CD10 & $1: 20 \mathrm{M}$ & Novocastra, Newcastle, UK \\
CD34 & $1: 320 \mathrm{M}$ & Dako Corp., Santa Barbara, CA, USA \\
CD99 & $1: 40 \mathrm{M}$ & Signet, Dedham, MA, USA \\
S-100 & $1: 800 \mathrm{P}$ & Dako Corp., Santa Barbara, CA, USA \\
& & \\
\hline
\end{tabular}

was considered negative. The stromal-like component showed $3+$ positivity in 6/8 tumors and the other two were $1+$ and $2+$, respectively. The percentage of positive cells varied from 5 to $90 \%$, five of them showing $>25 \%$ positive cells. In five out of eight tumors AE1/3 was expressed in both the epithelial and stromal-like cells.

CK7 was expressed in seven out of 13 tumors (Figure 1c). The epithelial component showed positive cells in six, five were $3+$, and one was $2+$; the percentage of positive cells ranged from 10 to $80 \%$, with three tumors having $>25 \%$ positive cells. The stromal-like component showed $3+$ positivity in five tumors, and $2+$ in one, ranging from 10 to $80 \%$, with only two tumors showing $>25 \%$ positive cells. One tumor showed scattered positive cells, and was considered negative. Both, stromal-like and epithelial components were positive in five tumors.

CK20 was positive in two out of 13 tumors. The epithelial component was positive in two tumors, $2+$ and $3+$ respectively. The percentage of positive cells ranged from 10 to $30 \%$. The stromal-type component was positive in one tumor and showed $2+$ positivity in $10 \%$ of the cells. One tumor showed scattered positive cells $(<1 \%)$ in the stromal-like component, and was considered negative. Positive staining in both epithelial and stromallike components was found in only one tumor.

EMA was positive in six out of 13 tumors. The epithelial component was positive in all six tumors, ranging from $1+$ to $3+$ (four being $2+$ ) in $5-60 \%$ of the tumor cells. Four tumors had $>25 \%$ positive cells. The stromal-like component revealed $1+$ staining in two tumors in $10 \%$ of the tumor cells. Two tumors with scattered positive stromal-like cells were considered negative. Only two tumors showed positivity in both components.

Muscle actin (MA) was positive in 11 out 12 tumors, showing $2+$ staining in $10 \%$ of the epithelial component in only one out of the seven tumors with an epithelial component present in the section for evaluation. The stromal-like component was positive in 11 out of 12 tumors ranging from $2+$ to $3+$ in $5-70 \%$ of the tumor cells; seven tumors

Table 2 Summary of immunohistochemical findings

\begin{tabular}{|c|c|c|c|c|}
\hline Antibody & Overall positivity & Epithelial component & Stromal-like component & Both components \\
\hline AE1/E3 & $8 / 12$ & $6(30-90 \%)$ & 8 (5-90\%) & 5 \\
\hline CK7 & $7 / 13$ & $6(10-80 \%)$ & $6(10-80 \%)$ & 5 \\
\hline CK20 & $2 / 13$ & $2(10-30 \%)$ & $1(10 \%)$ & 1 \\
\hline EMA & $7 / 13$ & $6(5-60 \%)$ & $2(10 \%)$ & 2 \\
\hline MA & $11 / 12$ & $1(10 \%)$ & $11(5-70 \%)$ & 1 \\
\hline Desmin & $10 / 11$ & $1(30 \%)$ & $10(5-70 \%)$ & 1 \\
\hline h-Caldesmon & $5 / 13$ & 0 & $5(5-50 \%)$ & 0 \\
\hline CD10 & $13 / 13$ & $6(30-100 \%)$ & $12(70-100 \%)$ & 5 \\
\hline CD34 & 7/11 & $1(30 \%)$ & $7(5-80 \%)$ & 1 \\
\hline CD99 & $0 / 7$ & 0 & 0 & 0 \\
\hline S-100 & $1 / 7$ & 0 & $1(10 \%)$ & 0 \\
\hline
\end{tabular}


had $>25 \%$ positive stromal-like cells. Only one tumor expressed MA in both the epithelial and stromal-like components.

Desmin stained 10 out of 11 tumors. Only one out of the seven tumors with an epithelial component present in the section for evaluation had positivity of the epithelial component $(30 \%, 2+)$ and 10 tumors showed positivity in the stromal-like component, with an intensity ranging from $2+$ to $3+$ (seven being $3+$ ) in $5-70 \%$ of the tumor cells (seven tumors had $>25 \%$ positive cells). In one tumor, the expression of desmin in the stromal-like component was $<1 \%$, and was considered negative. One tumor showed desmin in both epithelial and stromal-like components.

h-Caldesmon was expressed in five out of 13 tumors (Figure 1d). None showed expression in the epithelial component. The stromal-like component was positive in five tumors, ranging from $2+$ to $3+$, in $5-50 \%$ of the tumor cells, with only one tumor showing $>25 \%$ positive cells. In one case, the stromal-like component expressed $<1 \%$ positivity for h-Caldesmon, and was considered negative.

All 13 of 13 tumors showed positivity for CD10 (Figure 1e). The epithelial cells expressed CD10 in six cases ranging from $2+$ to $3+$, in $30-100 \%$ of the tumor cells. Twelve tumors showed positivity in the stromal-like cells, ranging from $2+$ to $3+$, in $70-$ $100 \%$ of the tumor cells. Five tumors showed positivity for CD10 in both stromal-like and epithelial components.

CD34 was expressed in seven out of 11 tumors (Figure 1f). The epithelial component showed positive staining in only one out of the six tumors with an epithelial component present in the section for evaluation $(30 \%, 3+)$. The stromal-like component showed CD34 positivity in seven tumors, ranging from $2+$ to $3+$, in $5-80 \%$ of the tumor cells, with five tumors showing $>25 \%$ positive cells. One neoplasm showed positivity for CD34 in both the stromal-like and epithelial components.

CD99 was negative for membranous staining in all tumors, but showed cytoplasmic straining in $7 / 8$ tumors in the stromal-like component.

S-100 was positive in the stromal-like component $(10 \%, 2+)$ in only one out of seven tumors.

\section{Discussion}

Although MTsV are well-known benign neoplasms, their histogenesis is still controversial. MTsV should be distinguished from mixed tumors at other sites, as the latter have a common origin from myoepithelial cells, and retain variable degrees of myoepithelial differentiation. ${ }^{19-21,23-28}$ These features are lacking in MTsV, even though initial reports supported a myoepithelial origin for these tumors by immunohistochemistry and/or ultrastructure. ${ }^{4,13}$ Recent studies have supported an epithelial origin of MTsV, favoring a urogenital sinus over a mullerian origin given the typical location around the hymenal ring and the likehood of epithelial migration during vaginal embryogenesis. ${ }^{1,9}$ Yet, it is of note that in most cases, the bulk of the tumor is composed of cells with a mesenchymal appearance, and that coexpression of actin and cytokeratin has been documented in a variety of tumors, not only pure epithelial tumors but also stromal predominant tumors. Finally, others have suggested that both the epithelial and stromal-type cells in MTsV may have an origin from a single multipotential cell, ${ }^{8}$ as discussed in the first series of MTsV reported by Sirota and colleagues more than 20 years ago. ${ }^{3}$

To date only one sizable study ${ }^{1}$ and a few individual cases of $\mathrm{MTsV}^{6-9,13,17}$ have been reported with relatively extensive immunohistochemical results (Table 3). We undertook this study to further delineate the immunohistochemical profile of MTsV in an attempt to elucidate the cell of origin and furthermore, to find out if there is a specific immunoprofile associated with MTsV that may help in distinguishing them from cellular smooth muscle tumors or other rarer tumors that may involve the vagina such as endometrial (endometrioid) stromal sarcoma particularly when dealing with small biopsy specimens or when the epithelial component is minimal and may be overlooked.

Keratins, initially used in the differential diagnosis of epithelial tumors with other neoplasms, mainly those of mesenchymal origin, may be positive in the latter including smooth muscle tumors and endometrial stromal tumors. ${ }^{29-33}$ The largest immunohistochemical analysis of $\mathrm{MTsV}$ reported by Branton and Tavassoli ${ }^{1}$ found intense reactivity with $\mathrm{AE} 1 / 3$ in nine out of $10 \mathrm{MTsV}$, while another tumor only showed sparse reactivity in the stromal-like component that was by far the predominant and in some cases the only component in these tumors. Similar results have been reported by others. $^{4,6-9,13,17}$ Our study also showed that $8 / 12$ $\mathrm{MTsV}$ were positive for AE1/3, being positive in the stromal-like areas in 8/12 tumors. However, as mentioned earlier, as keratins may be positive in mesenchymal tumors they are not definitive in identifying the origin of these tumors nor in the differential diagnosis with other vaginal tumors with a mesenchymal component specifically smooth muscle tumors and endometrioid (endometrial) stromal tumors.

CK7 is mainly expressed in myoepithelial cells and simple epithelia. ${ }^{29}$ In the vagina, squamous cell carcinoma expresses CK 7. Skelton and Smith reported intense but not diffuse positivity for CK7 in a MTV that was only composed of spindle cells and Murdoch et $a l^{17}$ reported CK7 positivity in both epithelial and stromal-like components. Our findings revealed that seven out $13 \mathrm{MTsV}$ were CK7 positive, but mostly focally. This degree of positivity is not meaningful to postulate an epithelial origin of these tumors. Furthermore, positivity has also been reported in nonepithelial tumors including synovial 
Table 3 Summary of immunohistochemical findings in MTsV

\begin{tabular}{|c|c|c|c|c|c|c|c|c|c|c|c|}
\hline & \multirow{2}{*}{$\begin{array}{c}\begin{array}{c}\text { Branton } \\
(\mathrm{n}=11)\end{array} \\
\begin{array}{c}\text { Component } \\
\text { not } \\
\text { specified }\end{array}\end{array}$} & \multicolumn{2}{|c|}{$\begin{array}{l}\text { Fukunaga } \\
(\mathrm{n}=1)\end{array}$} & \multicolumn{2}{|c|}{$\begin{array}{l}\text { Kang } \\
(\mathrm{n}=1)\end{array}$} & \multirow{2}{*}{$\begin{array}{c}\begin{array}{c}\text { Kawauchi } \\
(\mathrm{n}=1)\end{array} \\
\text { STR }\end{array}$} & \multicolumn{2}{|c|}{$\begin{array}{l}\text { Murdoch } \\
(\mathrm{n}=1)\end{array}$} & \multirow{2}{*}{$\begin{array}{c}\begin{array}{c}\text { Skelton } \\
(\mathrm{n}=1)\end{array} \\
\begin{array}{c}\text { Component } \\
\text { not } \\
\text { specified }\end{array}\end{array}$} & \multicolumn{2}{|c|}{$\begin{array}{c}\text { Oliva } \\
(\mathrm{n}=13)\end{array}$} \\
\hline & & $\mathrm{EPT}$ & STR & EPT & STR & & EPT & STR & & EPT & STR \\
\hline AE1/E3 & & + & - & + & + & + & + & + & + & $+(6)$ & $+(8)$ \\
\hline PKK-1 & ND & + & + & ND & ND & ND & & & ND & ND & ND \\
\hline CK7 & ND & ND & ND & ND & ND & ND & * & + & + & $+(6)$ & $+(6)$ \\
\hline CK20 & ND & & & ND & ND & ND & & - & $+1-$ & $+(2)$ & $+(1)$ \\
\hline EMA & ND & + & & ND & ND & ND & * & + & $\begin{array}{c}\text { (scattered } \\
\text { cells })\end{array}$ & $+(6)$ & $+(2)$ \\
\hline MA/SMA & + & - & - & - & - & + & & & + (stroma) & $+(1)$ & $+(11)$ \\
\hline $\begin{array}{l}\text { h- } \\
\text { Caldesmon }\end{array}$ & ND & ND & ND & ND & ND & ND & & & ND & - & $+(5)$ \\
\hline Desmin & ND & - & - & - & - & - & & & - & $+(1)$ & $+(10)$ \\
\hline CD10 & - & ND & & ND & ND & & * & + & ND & $+(6)$ & $+(12)$ \\
\hline CD34 & ND & - & - & - & - & - & * & + & + & - & - \\
\hline CD99 & ND & ND & & ND & ND & & * & - & + & - & - \\
\hline S100 & - & - & - & - & - & - & * & - & - & - & $+(1)$ \\
\hline Vimentin & ND & - & + & - & + & - & * & + & + & ND & ND \\
\hline GFAP & - & ND & ND & ND & ND & - & ND & ND & ND & ND & ND \\
\hline ER & $\begin{array}{c}\text { Weak to } \\
\text { absent } \\
(\mathrm{N}=5)\end{array}$ & ND & ND & ND & ND & - & + & + & + & ND & ND \\
\hline PR & $\begin{array}{l}\text { Diffuse } \\
(\mathrm{N}=5)\end{array}$ & ND & ND & ND & ND & - & + & + & + & ND & ND \\
\hline Bcl-2 & ND & ND & ND & ND & ND & ND & * & + & + & ND & ND \\
\hline
\end{tabular}

$\mathrm{N}=$ number of cases; EPT = epithelial component; STR = Stromal-like component; ND = not done; * Not specified

sarcoma, ${ }^{34}$ epithelioid angiosarcoma, ${ }^{33}$ and Wilms' tumor, the latter a neoplasm composed of primitivepluripotential cells. ${ }^{35}$ Regarding CK20, we only found CK20 positive cells in two out of $13 \mathrm{MTsV}$ and Skelton and Smith found minimal staining in the neoplasm they studied. Consequently, CK20 is not useful in the diagnosis or identifying the origin of MTsV.

EMA reacts with most epithelia and epithelial neoplasms ${ }^{36}$ but it is also expressed in nonepithelial tumors including smooth muscle tumors, more commonly those of the genital tract, ${ }^{31}$ and also in tumors with divergent differentiation such as synovial sarcomas ${ }^{37}$ and desmoplastic small round cell tumors. ${ }^{38}$ Nakashima et $a l^{6}$ reported positive staining in their MTV in both the stromal-type cells as well as in the epithelial cells; the one MTV reported by Skelton and Smith ${ }^{8}$ showed weak EMA expression in scattered cells and the most recent MTV reported by Murdoch et $a l^{17}$ showed positivity in both epithelial and stromal-like components. The present study revealed positivity in six out of 13 MTsV, mostly in the epithelial component. These results are not helpful in determining the histogenesis of these tumors or in the differential diagnosis with other tumors with a mesenchymal component as smooth muscle tumors of the female genital tract are positive for this antibody as already noted.

MA and desmin are two well-known markers of smooth muscle differentiation, although not $100 \%$ specific as they also stain myoepithelial cells and myoepithelial tumors and much less frequently epithelial neoplasms. The two MTsV reported by Skelton and Smith ${ }^{8}$ and Nakashima et al ${ }^{6}$ showed negative and minimal staining for MA respectively. However, Branton and Tavassoli ${ }^{1}$ noted intense smooth muscle actin positivity in all their tumors, and Murdoch et $a l^{17}$ showed actin positivity in the intermixed bundles of spindle cells. Our study also showed extensive MA positivity in 11 out of 12 MTsV, mainly in the stromal-like component. Desmin was negative in the tumors reported by Skelton and $\mathrm{Smith}^{8}$ and Fukunaga et $a l^{7}$ and although we found desmin positivity in 10/11 MTsV studied, this was mainly in the stromal-like component as seen in the MTV reported by Murdoch et al. ${ }^{17}$ These results may speak in favor of a myoepithelial origin for these neoplasms but do not exclude others, and they are not helpful in differentiating MTsV from other spindle cell tumors of the vagina.

h-Caldesmon, a smooth muscle marker thought to be restricted to vascular and visceral smooth muscle cells and myoepithelial cells, has not been previously studied in MTsV. Five out of $13 \mathrm{MTsV}$ in this series showed focal h-Caldesmon positivity. This finding suggests again the possibility of a myoepithelial origin of MTsV, but one would expect the expression of this antibody to be more extensive and present in the majority of the tumors if they were of myoepithelial origin. The extent of positivity for h-Caldesmon in these tumors makes this antibody not useful in the differential diagnosis of MTsV with other vaginal tumors with a mesenchymal component. 
CD10 is widely expressed in normal tissues such as myoepithelial cells of breast and parotid gland, and in many epithelial and nonepithelial tumors, ${ }^{39}$ although mixed tumors of the salivary gland are negative. In the female genital tract, CD10 reacts with endocervical and endometrial stromal cells, Wolffian remnants, and luteinized cells as well as with benign and malignant endocervical glandular lesions, endometrial adenocarcinomas, mullerian mixed tumors, endometrial stromal tumors, smooth muscle tumors, Wolffian tumors and sex-cord stromal tumors of the ovary. ${ }^{39-44}$ Our findings revealed extensive CD10 positivity in all MTsV (13 out of 13). To date, only one other very recent case report has shown CD10 positivity in MTsV. ${ }^{17}$ This finding is not helpful regarding the histogenesis of these tumors, because as mentioned earlier, CD10 is negative in tumors derived from myoepithelial cells and CD10 has been seen in both epithelial and nonepithelial tumors. Furthermore, CD10 is not useful in distinguishing MTsV from smooth or skeletal muscle tumors, or even endometrioid (endometrial) stromal tumors that can occur at this site. With regard to the latter differential, this study was prompted in part by a case sent in consultation to one of us in which the patient had a previous history of an endometrial stromal sarcoma of the uterus and presented later with a vaginal nodule. The differential diagnosis in that case included recurrent endometrial stromal sarcoma with epithelial differentiation and MTV. That issue led to us investigating whether CD10 was a reliable discriminant.

Several studies have shown CD34 reactivity in smooth muscle tumors and other mesenchymal lesions, but malignant epithelial tumors are almost always negative. ${ }^{45}$ In the female genital tract, CD34 is expressed in cervical stromal cells, basally located endometrial stromal cells and rare smooth muscle tumors, but it is negative in endometrial stromal sarcomas and aggressive angiomyxomas. ${ }^{41,46-49}$ Skelton and Smith ${ }^{8}$ found CD34 to be diffusely positive in their MTV and Murdoch et $a l^{17}$ reported the same findings. Our results showed positivity in seven out 11 MTsV (5-80\%), being $>25 \%$ in five tumors, mainly in the stromal-like component. Lindenmayer and Miettinen ${ }^{46}$ postulated that CD34 reactivity may be an inherent property of subsets of fibroblasts such as those of uterine stromal tissues, and although not all tumors in this series were CD34 positive, the presence of positivity in half of them may favor a mesenchymal origin of these tumors. As smooth muscle tumors may be positive for CD34, this antibody is not helpful in distinguishing MTsV from this tumor.

CD99, a sensitive marker of Ewing's sarcoma and peripheral primitive neuroectodermal tumors, is also expressed in epithelial and mesenchymal tumors, and those with divergent differentiation. ${ }^{30,38}$ In the female genital tract, it may be positive in ovarian sex-cord stromal tumors, ${ }^{50,51}$ uterine tumors resembling ovarian sex-cord tumors and smooth muscle tumors. ${ }^{41,52}$ Skelton and Smith $^{8}$ reported diffuse positivity for CD99 in one MTV. We found CD99 cytoplasmic expression in seven MTsV (10$60 \%$ ), but none of the tumors showed the typical membranous staining.

Finally, S-100, initially considered specific to glial cells, has been found in other types of cells, such as myoepithelial cells, melanocytes, chondrocytes, adypocites, striated muscle, and weakly in some epithelial cells. ${ }^{53}$ All MTsV previously reported were S-100 negative. Our results showed focal immunoreactivity in only one out of seven MTsV and argue against a myoepithelial origin for these neoplasms.

In conclusion, although positivity for CK7, MA, desmin and h-Caldesmon could favor a myoepithelial origin, S-100 negativity and diffuse CD10 positivity argues against it. An epithelial origin, suggested by some authors, is not certain as these tumors extensively express several mesenchymal markers. Our immunohistochemical results, in which stromal-type cells and epithelial cells coexpress different epithelial and mesenchymal markers, support the contention that MTsV may arise from a pluripotential cell that must have the ability to differentiate in both epithelial and mesenchymal directions. Their immunohistochemical profile is neither specific nor helpful in the differential diagnosis of MTsV from the more common vaginal smooth muscle tumors or even from other rare tumors. The final diagnosis must be based on a careful conventional microscopic evaluation of these neoplasms.

\section{Acknowledgement}

We are grateful to Dr Robert E Scully for allowing us to use material from his consultation files.

\section{References}

1 Branton PA, Tavassoli FA. Spindle cell epithelioma, the so-called mixed tumor of the vagina. A clinicopathologic, immunohistochemical, and ultrastructural analysis of 28 cases. Am J Surg Pathol 1993;17: 509-515.

2 Brown CE. Mixed epithelial tumor of the vagina. Am J Clin Pathol 1953;23:237-240.

3 Sirota RL, Dickersin GR, Scully RE. Mixed tumors of the vagina. A clinicopathological analysis of eight cases. Am J Surg Pathol 1981;5:413-422.

4 Watanabe H, Katsuda S, Okada Y, et al. Pleomorphic adenoma with a predominantly myoepithelial proliferation of the vagina. Acta Pathol Jpn 1987;37:685-692.

5 Kruslin B, Dzebro S, Juric G, et al. Vaginal mixed tumor or spindle cell epithelioma-a case report. Zentralbl Gynakol 1995;117:317-319.

6 Nakashima Y, Sueishi K, Morishita Y. A case report of mixed tumor arising in the vagina. Fukuoka Igaku Zasshi 1992;83:333-337. 
7 Fukunaga M, Endo Y, Ishikawa E, et al. Mixed tumour of the vagina. Histopathology 1996;28:457-461.

8 Skelton H, Smith KJ. Spindle cell epithelioma of the vagina shows immunohistochemical staining supporting its origin from a primitive/progenitor cell population. Arch Pathol Lab Med 2001;125:547-550.

9 Kang MS, Yoon HK. Mixed tumor of the vagina: a case report. J Korean Med Sci 2002;17:845-848.

10 Hertig AT, Gore H. Tumors of the vulva, vagina and uterus. In Atlas of Tumor Pathology, first series, fasc 33. Armed Forces Institute of Pathology: Washington, DC, 1960.

11 van den Broek N, Emmerson C, Dunlop W. Benign mixed tumour of the vagina: an unusual cause for postmenopausal bleeding. Eur J Obstet Gynecol Reprod Biol 1996;69:143-144.

12 Wright RG, Buntine DW, Forbes KL. Recurrent benign mixed tumor of the vagina. Gynecol Oncol 1991;40: 84-86.

13 Kawauchi S, Fukuda T, Tsuneyoshi M. Case report: a mixed tumor of the vagina. J Obstet Gynaecol Res 1998;24:223-229.

14 Chen KT. Benign mixed tumor of the vagina. Obstet Gynecol 1981;57:89S-90S.

15 Komiya H, Kawahara T, Magata H, et al. A case of rare vaginal mixed tumor. Iryo 1965;19:171.

16 Buntine DW, Henderson PR, Biggs JS. Benign Mullerian mixed tumor of the vagina. Gynecol Oncol 1979;8:21-26.

17 Murdoch F, Sharma R, Al-Nafussi A. Benign mixed tumor of the vagina: case report with expanded immunohistochemical profile. Int J Gynecol Cancer 2003;13:543-547.

18 Stead RH, Qizilbash AH, Kontozoglou T, et al. An immunohistochemical study of pleomorphic adenomas of the salivary gland: glial fibrillary acidic proteinlike immunoreactivity identifies a major myoepithelial component. Hum Pathol 1988;19:32-40.

19 Takai Y, Mori M, Dardick I, et al. Myofilament localization and immunoelectron microscopic detection of muscle-specific actin in neoplastic myoepithelial cells in pleomorphic adenomas and myoepitheliomas. Ultrastruct Pathol 1994;18:575-591.

20 Erlandson RA, Cardon-Cardo C, Higgins PJ. Histogenesis of benign pleomorphic adenoma (mixed tumor) of the major salivary glands. An ultrastructural and immunohistochemical study. Am J Surg Pathol 1984;8: 803-820.

21 Diaz NM, McDivitt RW, Wick MR. Pleomorphic adenoma of the breast: a clinicopathologic and immunohistochemical study of 10 cases. Hum Pathol 1991;22:1206-1214.

22 Cuadros CL, Ryan SS, Miller RE. Benign mixed tumor (pleomorphic adenoma) of the breast: ultrastructural study and review of the literature. J Surg Oncol 1987;36:58-63.

23 Wilk M, Klesper D, Uerlich M, et al. Chondroid syringoma. Immunohistologic indications of myoepithelial differentiation. Hautarzt 1994;45:324-329.

24 Rorat E, Wallach RC. Mixed tumors of the vulva: clinical outcome and pathology. Int J Gynecol Pathol 1984;3:323-328.

25 Collins RJ, Yu HC. Pleomorphic adenoma of the external auditory canal. An immunohistochemical and ultrastructural study. Cancer 1989;64:870-875.

26 Heifetz SA, Collins B, Matt BH. Pleomorphic adenoma (benign mixed tumor) of the trachea. Pediatr Pathol 1992;12:563-574.
27 Tosaka Y. Immunohistochemical study of pleomorphic adenoma of lacrimal gland. Jpn J Ophthalmol 1991;35:367-376.

28 Kilpatrick SE, Hitchcock MG, Kraus MD, et al. Mixed tumors and myoepitheliomas of soft tissue: a clinicopathologic study of 19 cases with a unifying concept. Am J Surg Pathol 1997;21:13-22.

29 Chu PG, Weiss LM. Keratin expression in human tissues and neoplasms. Histopathology 2002;40: 403-439.

30 Machen SK, Fisher C, Gautam RS, et al. Utility of cytokeratin subsets for distinguishing poorly differentiated synovial sarcoma from peripheral primitive neuroectodermal tumour. Histopathology 1998;33: 501-507.

31 Iwata J, Fletcher CD. Immunohistochemical detection of cytokeratin and epithelial membrane antigen in leiomyosarcoma: a systematic study of 100 cases. Pathol Int 2000;50:7-14.

32 Binder SW, Nieberg RK, Cheng L, et al. Histologic and immunohistochemical analysis of nine endometrial stromal tumors: an unexpected high frequency of keratin protein positivity. Int $\mathrm{J}$ Gynecol Pathol 1991;10:191-197.

33 Lin O, Gerhard R, Coelho Siqueira SA, et al. Cytologic findings of epithelioid angiosarcoma of the thyroid. A case report. Acta Cytol 2002;46:767-771.

$34 \mathrm{Ng}$ SB, Ahmed Q, Tien SL, et al. Primary pleural synovial sarcoma. A case report and review of the literature. Arch Pathol Lab Med 2003;127:85-90.

35 Rubin BP, Pins MR, Nielsen GP, et al. Isochromosome $7 \mathrm{q}$ in adult Wilms' tumors: diagnostic and pathogenetic implications. Am J Surg Pathol 2000;24: 1663-1669.

36 Pinkus GS, Kurtin PJ. Epithelial membrane antigen-a diagnostic discriminant in surgical pathology: immunohistochemical profile in epithelial, mesenchymal, and hematopoietic neoplasms using paraffin sections and monoclonal antibodies. Hum Pathol 1985;16: 929-940.

37 Essary LR, Vargas SO, Fletcher CD. Primary pleuropulmonary synovial sarcoma: reappraisal of a recently described anatomic subset. Cancer 2002;94: 459-469.

38 Lae ME, Roche PC, Jin L, et al. Desmoplastic small round cell tumor: a clinicopathologic, immunohistochemical, and molecular study of 32 tumors. Am J Surg Pathol 2002;26:823-835.

39 Chu P, Arber DA. Paraffin-section detection of CD10 in 505 nonhematopoietic neoplasms. Frequent expression in renal cell carcinoma and endometrial stromal sarcoma. Am J Clin Pathol 2000;113:374-382.

40 Ordi J, Romagosa C, Tavassoli FA, et al. CD10 expression in epithelial tissues and tumors of the gynecologic tract: a useful marker in the diagnosis of mesonephric, trophoblastic, and clear cell tumors. Am J Surg Pathol 2003;27:178-186.

41 Oliva E, Young RH, Amin MB, et al. An immunohistochemical analysis of endometrial stromal and smooth muscle tumors of the uterus: a study of 54 cases emphasizing the crucial importance of using a panel because of overlap in immunoreactivity for individual antibodies. Am J Surg Pathol 2002;26: 403-412.

42 Oliva E, Vu Q, Young RH. CD10 expression in sex cordstromal tumors (SCTs) and steroid cell tumors (SCTs) of the ovary. Mod Pathol 2002;15:204A. 
43 Mikami Y, Hata S, Kiyokawa T, et al. Expression of CD10 in malignant mullerian mixed tumors and adenosarcomas: an immunohistochemical study. Mod Pathol 2002;15:923-930.

44 McCluggage WG, Oliva E, Herrington CS, et al. CD10 and calretinin staining of endocervical glandular lesions, endocervical stroma and endometrioid adenocarcinomas of the uterine corpus: CD10 positivity is characteristic of, but not specific for, mesonephric lesions and is not specific for endometrial stroma. Histopathology 2003;43:144-150.

45 van de Rijn M, Rouse RV. CD34. A review. Appl Immunohistochem 1994;2:71-80.

46 Lindenmayer AE, Miettinen M. Immunophenotypic features of uterine stromal cells. CD34 expression in endocervical stroma. Virchows Arch 1995;426:457-460.

47 Barth PJ, Ramaswamy A, Moll R. CD34(+) fibrocytes in normal cervical stroma, cervical intraepithelial neoplasia III, and invasive squamous cell carcinoma of the cervix uteri. Virchows Arch 2002;441:564-568.

48 Oliva E, Young RH, Clement PB, et al. Myxoid and fibrous variants of endometrial stromal tumors of the uterus: a report of 10 cases. Int J Gynecol Pathol 1999;18:310-319.

49 Rizeq MN, van de Rijn M, Hendrickson MR, et al. A comparative immunohistochemical study of uterine smooth muscle neoplasms with emphasis on the epithelioid variant. Hum Pathol 1994;25: 671-677.

50 Loo KT, Leung AK, Chan JK. Immunohistochemical staining of ovarian granulosa cell tumours with MIC2 antibody. Histopathology 1995;27:388-390.

51 Deavers M, Malpica A, Liu J, et al. Ovarian sex cordstromal tumors: an immunohistochemical study including a comparison of calretin and inhibin. Mod Pathol 2003;16:584-590.

52 McCluggage WG. Uterine tumours resembling ovarian sex cord tumours: immunohistochemical evidence for true sex cord differentiation. Histopathology 1999;34: $375-376$.

53 Haimoto H, Hosoda S, Kato K. Differential distribution of immunoreactive S100-alpha and S100-beta proteins in normal nonnervous human tissues. Lab Invest 1987;57:489-498. 